\title{
An Acyllactam-Type Growable End Group Formed in the Anionic Polymerization of a Bicyclic Oxalactam. The Isolation of the Polyamide and Its Use as an Activator in the Polymerization of 2-Pyrrolidone
}

\author{
Kazuhiko Hashimoto, Hiroshi Sumitomo, and Housei ShINOdA \\ Faculty of Agriculture, Nagoya University, \\ Furo-cho, Chikusa-ku, Nagoya 464-01, Japan
}

(Received August 31, 1987)

\begin{abstract}
A bicyclic oxalactam, 8-oxa-6-azabicyclo[3.2.1]octan-7-one was anionically polymerized in dimethyl sulfoxide at room temperature and the resulting hydrophilic polyamide having an acyllactam-type growable chain end was isolated from the polymerization system. The reactive end group was found to be easily converted to other functional groups by the hydrolysis or aminolysis with suppressing the simultaneous decomposition of the polyamide chain. The terminal acyllactam group in the polyamide, which was used as an activator in the anionic polymerization of 2-pyrrolidone, was quantitatively consumed and all of the macromolecular activator could be incorporated into the resulting copolymer. The thermal behavior and crystallization of the AB-type block copolymer composed of the hydrophilic polyamide and nylon-4 segments were influenced by the characteristics of the hydrophilic polyamide segment.
\end{abstract}

KEY WORDS Bicyclic Oxalactam / Anionic Polymerization / Reactive End Group / 2-Pyrrolidone / Block Copolymer /

The polymerizability of a bicyclic oxalactam, 8-oxa-6-azabicyclo[3.2.1] octan-7-one (abbreviated as BOL, 1), is so high that it can be easily polymerized using anionic catalysts under mild conditions such as in dimethyl sulfoxide $\left(\mathrm{Me}_{2} \mathrm{SO}\right)$ at room temperature, ${ }^{1-3}$ which should be desirable for suppressing possible side reactions. In fact, the resulting hydrophilic high molecular weight polymer (polyBOL, 2) has a purely alternating arrangement of an amide group and a tetrahydropyran ring along the main chain but has no other repeating unit (eq 1)..$^{1-3}$

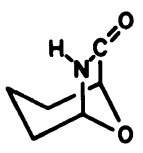

1

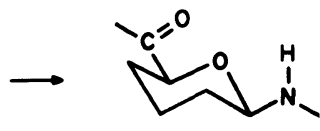

2
The vinylbenzyl-type polyamide macromer (3) was prepared by the anionic polymerization of $\mathrm{BOL}$ followed by the reaction with $p$-vinylbenzylamine. ${ }^{4,5}$ This suggests that the generated acyllactam-type growable chain end is not destroyed by any side reaction during
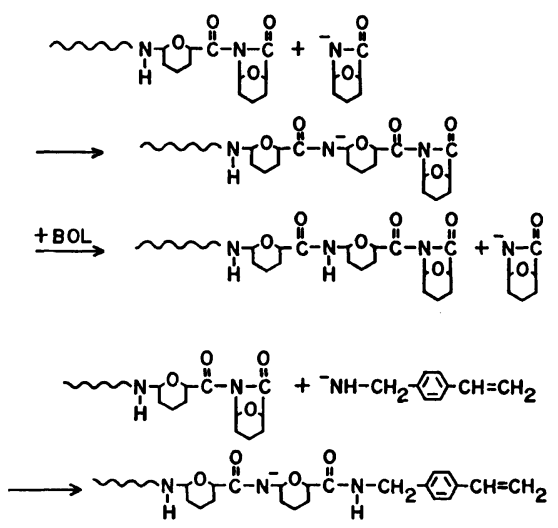


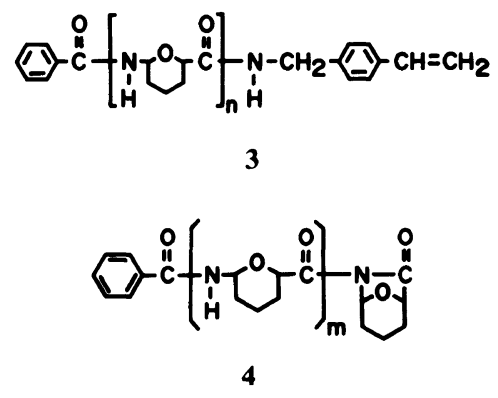

the polymerization, but still remains in the system until it reacted with the amine (eq 2 and 3 ). Therefore the polyamide having a growable end group (4) can be presumed to be isolated by careful treatment after the polymerization of BOL.

Although the growable end groups in the anionic polymerization of lactams are known to be their acyllactams, ${ }^{6-9}$ they have never been used for the preparation of block copolymers. The present article describes the isolation of the hydrophilic polyamide having a terminal acyllactam group (4) from the polymerization system of BOL and the use of the polyamide as an activator in the anionic polymerization of 2-pyrrolidone to give an AB-type block copolymer composed of a hydrophilic polyamide and nylon-4 segments (5). The chemical modification of the reactive end group to other functional groups by the

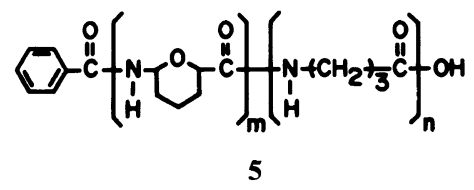

hydrolysis or aminolysis is also mentioned.

\section{RESULTS AND DISCUSSION}

\section{Preparation and Isolation of the Polyamide} Having a Terminal Acyllactam Group

The anionic polymerization of $\mathrm{BOL}$ was carried out using various amounts of $N$ benzoyl-8-oxa-6-azabicyclo[3.2.1]octan-7-one (BzBOL) as an activator in $\mathrm{Me}_{2} \mathrm{SO}$ at $25^{\circ} \mathrm{C}$ for $30 \mathrm{~min}$ as presented in Table I. In order to isolate the polyamide having an acyllactamtype growable end, the polymerization mixture was poured into a large amount of dry acetone after quenching by the addition of acetic acid. The precipitated polyamide was quickly collected by centrifugation, washed with fresh acetone, and dried in vacuo.

A typical ${ }^{1} \mathrm{H}$ NMR spectrum of the resulting polymer is shown in Figure 1. The small peaks $\mathrm{a}, \mathrm{c}, \mathrm{d}, \mathrm{e}, \mathrm{f}$, and $\mathrm{h}$ indicate that the acyllactam-type growable chain end exists in the polyamide as well as the benzamide group, which is the activator residue at the other chain end. Other possible terminal groups such as car-

Table I. Preparation of polyamide having an acyllactam group at either or both of chain ends by the anionic polymerization of $\mathrm{BOL}^{\mathrm{a}}$

\begin{tabular}{|c|c|c|c|c|c|c|c|}
\hline BOL & $\mathrm{BzBOL}$ & $\mathrm{Me}_{2} \mathrm{SO}$ & Polymer yield ${ }^{b}$ & & & & $\bar{M}_{w}{ }^{\mathbf{f}}$ \\
\hline g & $\mathrm{mol}^{\%} \%$ & $\mathrm{~g}$ & $\mathrm{~g}$ & & & & $M_{n}$ \\
\hline 6.35 & 1.5 & 20 & 5.99 & 68 & 1.0 & 8700 & 1.31 \\
\hline 6.35 & 2.0 & 20 & 6.00 & 52 & 1.00 & 6700 & 1.29 \\
\hline 6.24 & 5.0 & 20 & 4.19 & 27 & 0.94 & 3600 & 1.33 \\
\hline 6.35 & $2.0^{\mathrm{g}}$ & 20 & 5.75 & 56 & 2.03 & 7200 & 2.23 \\
\hline
\end{tabular}

a Potassium pyrrolidonate, $1 \mathrm{~mol} \%$ to monomer; temperature, $25^{\circ} \mathrm{C}$; time, $30 \mathrm{~min}$.

b Dry acetone was used as a precipitant at room temperature.

c Degree of polymerization of the polyamide.

d Determined by ${ }^{1} \mathrm{H}$ NMR spectroscopy.

e Functionality of terminal acyllactam group.

f Determined by GPC.

g $N, N^{\prime}$-Terephthaloylbis( $\varepsilon$-caprolactam) was used as an activator. 
boxyl group are not detected in the spectrum.

The split of peak e should be due to the diastereomeric terminal diad structures composed of the acyllactam unit and its penultimate repeating unit in the polymer chain, because BOL used in the present investigation is racemic. A similar split of the corresponding methine proton peak has also been observed in the ${ }^{1} \mathrm{H}$ NMR spectrum of the diastereomeric dimers prepared by the cationic oligomerization of BOL. ${ }^{10}$ The split of the peak $\mathrm{e}$ in Figure 1 is presumed to occur in preference to that of the other peaks not only due to its highdiastereomeric environment but also due to its small coupling constants with protons at the adjacent atoms.

Table II. Chemical shifts and assignments of peaks in the ${ }^{13} \mathrm{C}$ NMR spectra of the polyamide having an acyllactam end group and model compounds of its terminal groups ${ }^{\mathbf{a}, \mathbf{b}}$

\begin{tabular}{|c|c|c|c|}
\hline \multirow{2}{*}{ Peak } & $\begin{array}{c}\text { Polyamide } \\
4\end{array}$ & $\begin{array}{l}\text { Model compound } \\
6\end{array}$ & $\begin{array}{c}\text { Model compound } \\
7\end{array}$ \\
\hline & $\delta, \mathrm{ppm}$ & $\delta, \mathrm{ppm}$ & $\delta, \mathrm{ppm}$ \\
\hline \multirow[t]{4}{*}{ Carbonyl carbon } & a $\quad 171.18$ & - & a $\quad 171.81$ \\
\hline & b $\quad 169.28$ & - & - \\
\hline & c 167.9 & - & c 167.76 \\
\hline & d $\quad 165.41$ & d $\quad 165.42$ & - \\
\hline \multirow[t]{4}{*}{ Aromatic carbon } & e 133.64 & e 133.60 & - \\
\hline & f $\quad 131.71$ & f $\quad 131.27$ & - \\
\hline & g $\quad 127.84$ & g $\quad 127.92$ & - \\
\hline & h 127.23 & h 127.33 & - \\
\hline \multirow[t]{6}{*}{ Methine carbon } & $\begin{array}{l}\text { i } \quad 87.2\end{array}$ & - & i $\quad 86.96$ \\
\hline & j $\quad 78.48$ & j $\quad 78.32$ & - \\
\hline & k $\quad 77.37$ & - & - \\
\hline & 176.7 & - & 76.64 \\
\hline & m $\quad 76.21$ & $\mathrm{~m} \quad 76.30$ & - \\
\hline & $\mathrm{n} \quad 75.1$ & - & - \\
\hline \multirow[t]{6}{*}{ Methylene carbon } & o $\quad 29.74$ & o $\quad 29.62$ & - \\
\hline & p $\quad 27.42$ & p $\quad 27.87$ & - \\
\hline & q $\quad 25.27$ & - & q $\quad 25.22$ \\
\hline & $\begin{array}{ll}\mathrm{r} & 23.75\end{array}$ & - & 23.75 \\
\hline & $\mathrm{s} \quad 22.03$ & s $\quad 22.34$ & - \\
\hline & $\mathrm{t} \quad 15.11$ & - & $\mathrm{t} \quad 15.15$ \\
\hline
\end{tabular}

a Solvent, $\mathrm{Me}_{2} \mathrm{SO}-d_{6}$; tetramethylsilane; room temperature; $50 \mathrm{MHz}$.

b

f

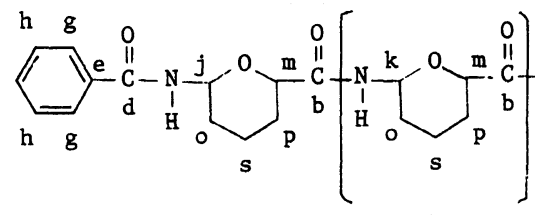

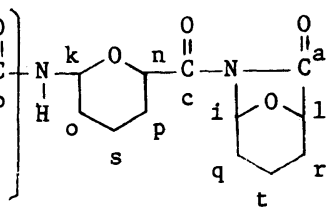

4<smiles>CCCNC(=O)[C@H]1CCCC(N(C)C(=O)c2ccccc2)O1</smiles><smiles>CC(=O)N1C(=O)[C@@H]2CCC[C@@H]1C2</smiles> 


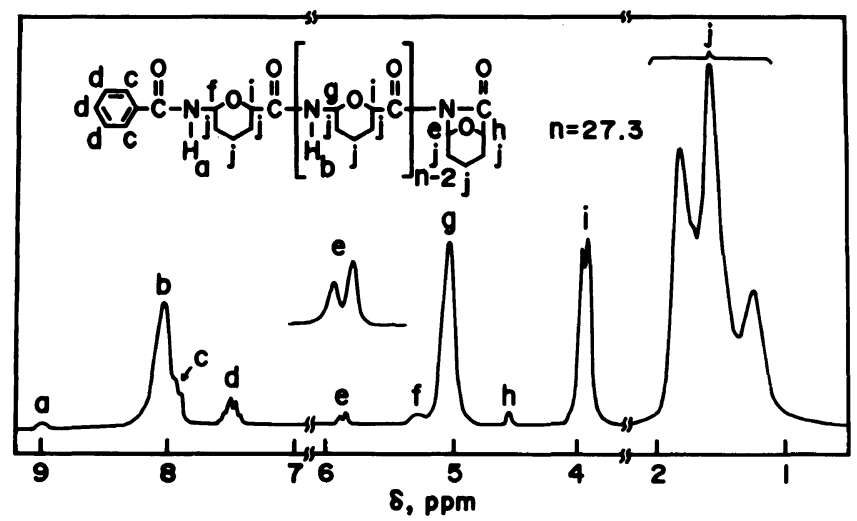

Figure 1. ${ }^{1} \mathrm{H}$ NMR spectrum of a polyamide having a terminal acyllactam group obtained by the anionic polymerization of BOL using $N$-benzoyl $\mathrm{BOL}$ as an activator $\left(6 \% \mathrm{Me}_{2} \mathrm{SO}-d_{6}\right.$ solution, tetramethylsilane, room temperature, $200 \mathrm{MHz}$ ).

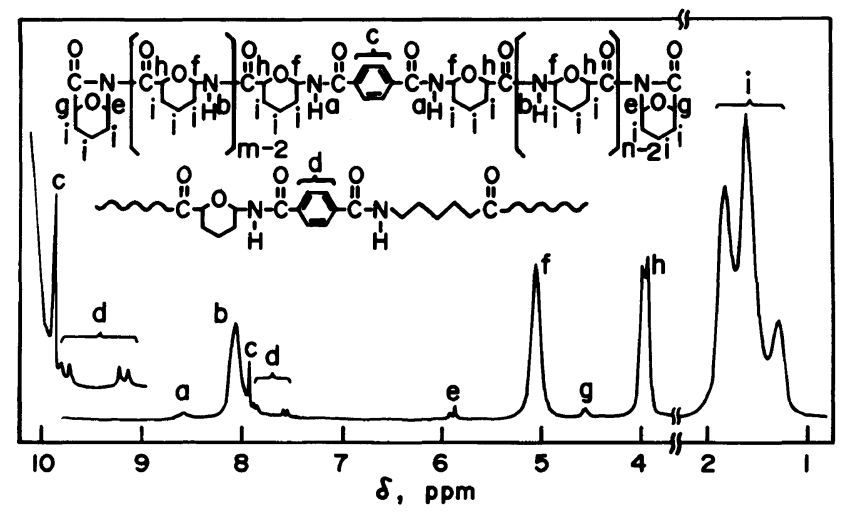

Figure 2. ${ }^{1} \mathrm{H}$ NMR spectrum of a polyamide telechelated with acyllactam groups obtained by the anionic polymerization of $\mathrm{BOL}$ using terephthaloylbis( $\varepsilon$-caprolactam) as an activator $\left(7 \% \mathrm{Me}_{2} \mathrm{SO}-d_{6}\right.$ solution, tetramethylsilane, room temperature, $200 \mathrm{MHz}$ ).

As listed in Table II, all peaks in the ${ }^{13} \mathrm{C}$ NMR spectrum of the polyamide are also assignable to the repeating BOL unit and both terminal groups. The chemical shifts of characteristic small peaks were found to correspond exactly to those in the spectra of their model compounds, $\mathrm{N}$-butyl-6-benzoylaminotetrahydropyran-2-carboxamide (6) and $\mathrm{N}$-acetyl8-oxa-6-azabicyclo[3.2.1] octan-7-one (AcBOL, 7). This also suggests that the isolated polyamide is the desirable one, 4 . Both contents of the benzamide and acyllactam groups in the polyamide were determined from the relative peak intensities in the expanded ${ }^{1} \mathrm{H}$ NMR spectrum. The degree of polymerization of the polyamide $(n)$ and the acyllactam functionality (the number of the acyllactam group per polymer chain, $x$ ) can be estimated using the following equation (eq 4), provided the benzamide group is located at one end of each polymer chain:

$$
\mathrm{D}:(\mathrm{E}+\mathrm{H}):(\mathrm{F}+\mathrm{G})=3: 2 x: n-x
$$

where $\mathrm{D}, \mathrm{E}, \mathrm{F}, \mathrm{G}$, and $\mathrm{H}$ are the relative intensities of peaks d, e, f, g, and h in Figure 1, respectively.

As shown in Table I, the average molecular weight of the polyamide was found to be 
controlled by the amount of BzBOL used as an activator, which was observed also in the preparation of the vinylbenzyl-type polyamide macromer. ${ }^{5}$ The acyllactam functionality was almost unity independent of the amount of the activator used. Therefore the acylactam-type growable end group can be presumed not to be destroyed not only during the polymerization but also during the nimble treatment of the isolation of the polyamide using dry actone as a precipitant.

In order to prepare the polyamide telechelated with acyllactam groups, the anionic polymerization of BOL was attempted first by using $N, N^{\prime}$-terephthaloylbis(8-oxa-6-azabicyclo[3.2.1] octan-7-one) as an activator, but its solubility in $\mathrm{Me}_{2} \mathrm{SO}$ is too low to be used as an activator. Therefore $N, N^{\prime}-$ terephthaloylbis( $\varepsilon$-caprolactam) was used as an activator for the anionic polymerization as shown in Table I and Figure 2. From the estimation of the functionality the acyllactam groups were found to remain at both chain ends of the resulting polyamide as expected. But the molecular weight distribution is much wider than that of the above-described polyamide having one growable chain end, which

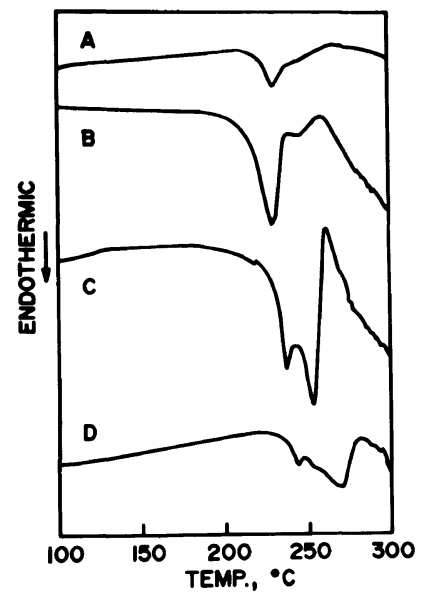

Figure 3. Effect of the terminal structure upon the thermal behavior of polyBOL. Terminal group: A, acyllactam $\left(\bar{M}_{n}, 6700\right)$; B, carboxylate $\left(\bar{M}_{n}, 4300\right)$; C, carboxyl group $\left(\bar{M}_{n}, 4300\right)$; D, $N$ - $n$-butylamide $\left(\bar{M}_{n}, 3400\right)$. means decrease of the reactivity of one acyllactam group in the activator after the consumption of the other one. In addition the polyamide was found from the ${ }^{1} \mathrm{H}$ and ${ }^{13} \mathrm{C}$ NMR spectroscopic analyses to be contaminated with a trace amount of other repeating unit originating from $\varepsilon$-caprolactam.

\section{Chemical Modification of the Acyllactam Group in PolyBOL}

The isolated polyBOL having an acyllactam group decomposed to the monomer at $230^{\circ} \mathrm{C}$ as shown in Figure 3(A). The temperature is still lower than the transition points for the high molecular weight polyBOL (mp 260 $285^{\circ} \mathrm{C}$ and decomp. p. $\left.310^{\circ} \mathrm{C}\right){ }^{1}$ However polyBOL isolated in the present work is sufficiently stable at room temperature. Therefore the acyllactam group at the chain end could be converted to other groups such as carboxyl group without a decomposition of the polyamide chain as described later (eq 5).

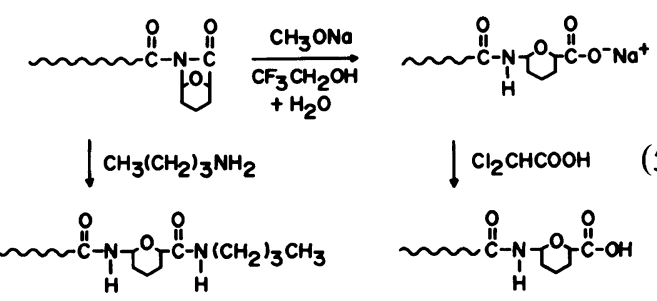

PolyBOL having an acyllactam terminal group was hydrolyzed with sodium methoxide in the trifluoroethanol-water mixed solvent at room temperature overnight and the reaction was quenched by the addition of dichloroacetic acid $\left(p K_{\mathrm{a}}, 1.26\right)$. The ${ }^{1} \mathrm{H}$ NMR spectrum of the recovered polyBOL has no proton peak due to the acyllactam group but a broad peak assignable to the carboxylic acid proton at $\delta 12.6 \mathrm{ppm}$ as shown in Figure 4(A). However, neither proton peaks due to the acyllactam and carboxylic acid are observed in the ${ }^{1} \mathrm{H}$ NMR spectrum of polyBOL recovered after the alkaline hydrolysis and quenching with acetic acid $\left(p K_{\mathrm{a}}, 4.74\right)$ or monochloroacetic acid $\left(p K_{\mathrm{a}}, 2.86\right)$. This fact suggests that 
the terminal group in the polyamide is the sodium salt of the carboxylic acid, of which $p K_{\mathrm{a}}$ value is between 1.26 and 2.86. In fact,

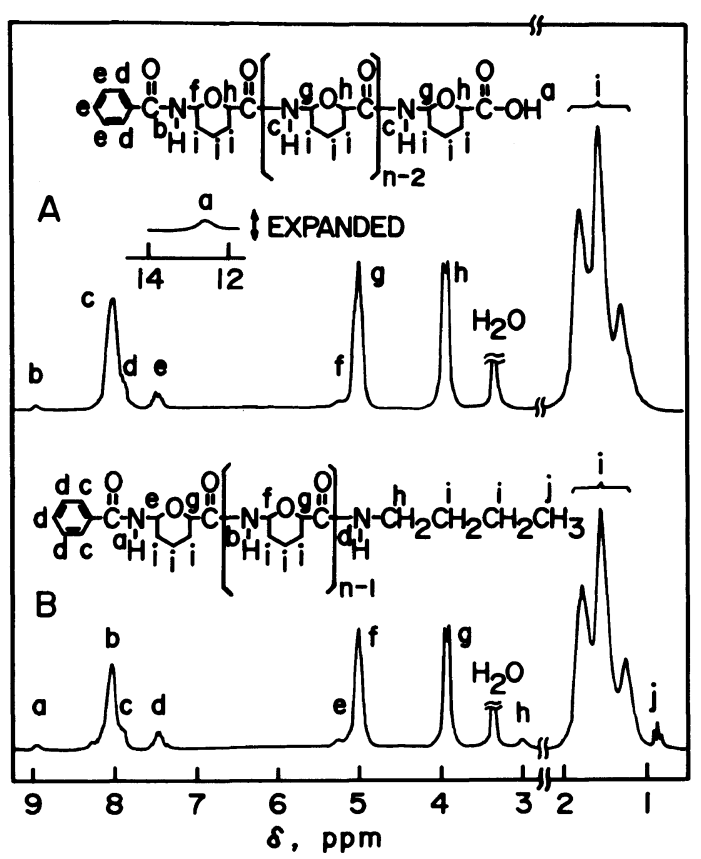

Figure 4. ${ }^{1} \mathrm{H}$ NMR spectra of polyBOL recovered after the modification of the terminal acyllactam group $\left(6-7 \% \mathrm{Me}_{2} \mathrm{SO}-d_{6}\right.$ solution, tetramethylsilane, room temperature, $200 \mathrm{MHz}$ ). A, after hydrolysis with sodium methoxide followed by neutralization with dichloroacetic acid; $\mathrm{B}$, after aminolysis with $n$-butylamine.
polyBOL having a carboxylate group was decomposed at $229^{\circ} \mathrm{C}$ to the monomer, while the transition points of polyBOL having a carboxyl group are 237 and $253^{\circ} \mathrm{C}$ as shown in Figure 3 ( $\mathrm{B}$ and $\mathrm{C}$ ). These results are consistent with the report that a carboxylate accelerates the decomposition of nylon- 6 at high temperature. $^{11}$ Of course the acyllactam-type end group can be modified to the amide group by aminolysis with $n$-butylamine at room temperature (see Figure 4(B)) as well as with $p$ vinylbenzylamine and ethylene diamine in the previous papers., ${ }^{4,12}$ This chemical modification is also characterized by the thermal analysis as shown in Figure 3(D). Such a reactive acyllactam-type end group in the isolated polyamide will be useful for various polyamide reactions.

Anionic Polymerization of 2-Pyrrolidone with Use of PolyBOL Having a Terminal Acyllactam as an Activator

Since the acyllactam group is essentially a growable chain end in the anionic polymerization of lactams, the isolated polyBOL having a terminal acyllactam, 4 , can be presumed to be used as an activator in the anionic polymerization of other lactams as far as it is

Table III. Anionic polymerization of 2-pyrrolidone with use of polyBOL having a terminal acyllactram as an activator $^{\mathrm{a}}$

\begin{tabular}{|c|c|c|c|c|c|c|c|c|c|c|}
\hline \multirow{2}{*}{$\frac{\text { Pyrdn }^{b}}{\mathrm{~g}}$} & \multicolumn{3}{|c|}{ PolyBOL } & \multirow{2}{*}{$\frac{\mathrm{BzBOL}}{\mathrm{mg}\left(\mathrm{mol}^{\circ} \mathrm{o}\right)}$} & \multirow{2}{*}{$\begin{array}{c}\begin{array}{c}\text { Convn. } \\
\text { of Pyrdn }\end{array} \\
\frac{\%}{\%}\end{array}$} & \multirow{2}{*}{$\begin{array}{c}\begin{array}{c}\text { Copolym. } \\
\text { yield }^{\mathbf{e}}\end{array} \\
\mathrm{g}\end{array}$} & \multirow{2}{*}{$\begin{array}{c}\begin{array}{l}\text { Recovered } \\
\text { polyBOL }\end{array} \\
\mathrm{g}\end{array}$} & \multirow{2}{*}{$y^{\mathbf{g}}$} & \multirow{2}{*}{$w^{\mathrm{h}, \mathrm{i}}$} & \multirow{2}{*}[\eta]{$^{\mathrm{j}}$} \\
\hline & $\bar{M}_{n}$ & $x^{\mathbf{c}}$ & $g^{d}$ & & & & & & & \\
\hline 11.1 & 3600 & 0.94 & 0.49 & 0 & 72 & 8.52 & 0.03 & 0.94 & $0.07(0.05)$ & 3.89 \\
\hline 10.4 & - & - & 0 & $28(0.1)$ & 37 & - & - & - & - & 2.46 \\
\hline 11.6 & 6700 & 1.00 & 0.91 & 0 & 48 & 6.42 & 0.04 & 0.96 & $0.17(0.14)$ & 2.55 \\
\hline 13.0 & 8700 & 1.0 & 1.33 & 0 & 24 & 4.43 & 0.03 & 0.98 & $0.30(0.29)$ & 1.54 \\
\hline
\end{tabular}

a Potassium pyrrolidonate, $2 \mathrm{~mol} \%$ to 2-pyrrolidone; temperature, $30^{\circ} \mathrm{C}$; time, $24 \mathrm{~h}$.

b 2-Pyrrolidone. ${ }^{\mathrm{c}}$ Acyllactam functionality. ${ }^{\mathrm{d}} 0.1 \mathrm{~mol} \%$ to 2 -pyrrolidone.

e Insoluble in chloroform. ${ }^{\mathrm{f}}$ Soluble in chloroform.

B Efficiency of block copolymerization estimated by the weight ratio of the polyBOL segment in the copolymer to the used macromolecular activator.

${ }^{\mathrm{h}}$ Weight fraction of BOL unit in copolymer determined by ${ }^{1} \mathrm{H}$ NMR spectroscopy.

i Figures in parentheses were gravimetrically determined.

${ }^{j}$ Measured in $m$-cresol at $25^{\circ} \mathrm{C}$. 
soluble in the reaction systems. The polyamide 4 is more soluble than nylon-4 in 2-pyrrolidone, although the solubility decreases with the increase of its molecular weight. Therefore, in the present work, 2-pyrrolidone was anionically polymerized using the polyamide $4(0.1$ $\mathrm{wt} \%$ to the monomer) as an activator at $30^{\circ} \mathrm{C}$ for 1 day as summarized in Table III.

The conversion in the polymerization of 2pyrrolidone using the macromolecular activator, of which molecular weight was 3600 , was found to be twice higher than that using $\mathrm{BzBOL}$ as the corresponding low molecular weight activator. The former polymerization is presumed to proceed in homogeneous phase to relatively high conversion, since the polyamide obtained in the former polymerization is more soluble than that obtained in the latter one. The conversion, however, decreased with increase of the molecular weight of the macromolecular activator. Therefore in the polymer-

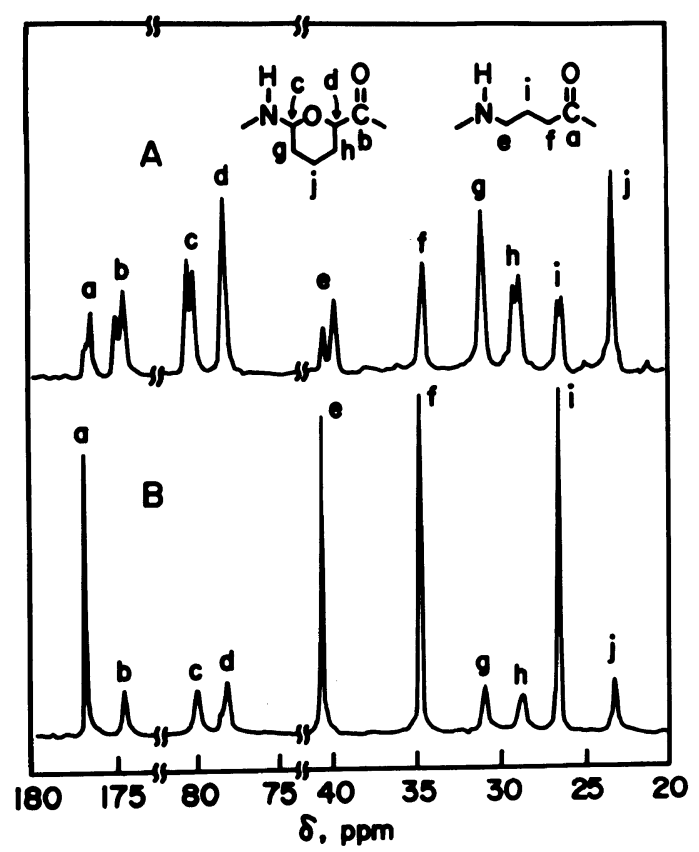

Figure 5. ${ }^{13} \mathrm{C}$ NMR spectra of copolymers of BOL and 2-pyrrolidone (solvent, 2,2,2-trifluoroethanol; temperature, $40^{\circ} \mathrm{C} ; 50 \mathrm{MHz}$ ). A, random copolymer (mole fraction of BOL unit, $m=0.66) ; \mathrm{B}$, block copolymer $(m=$ 0.42). ization of 2-pyrrolidone activated by a higher molecular weight polyBOL, the resulting polyamide may be deposited from the polymerization system in relatively low conversion because of its low solubility in 2-pyrrolidone.

Although a trace amount of the unreacted polyBOL was recovered by the repeated extraction with chloroform, a large amount of the macromolecular activator was assumed to be incorporated into the resulting polymer from the polymer yield and the copolymer composition determined by both of gravimetric and ${ }^{1} \mathrm{H}$ NMR spectroscopic methods.

The ${ }^{13} \mathrm{C}$ NMR spectrum of the isolated copolymer is compared with that of the random copolymer previously prepared by the anionic copolymerization of BOL and 2-pyrrolidone, ${ }^{13}$ as shown in Figure 5. The former is just the spectrum of nylon- 4 superposed upon that of polyBOL, while some splittings of the corresponding peaks due to the different mi-

Table IV. Chemical shifts and assignments on ${ }^{13} \mathrm{C}$ NMR spectra of the homopolymers and copolymers of BOL and 2-pyrrolidone ${ }^{\mathrm{a}}$

\begin{tabular}{|c|c|c|c|c|}
\hline \multirow{2}{*}{ Peak $^{b}$} & \multirow{2}{*}{$\frac{\text { PolyBOL }}{\delta, \mathrm{ppm}}$} & \multirow{2}{*}{$\frac{\text { Nylon-4 }}{\delta, \mathrm{ppm}}$} & \multirow{2}{*}{$\frac{\begin{array}{c}\text { Random } \\
\text { copolymer }^{\mathrm{c}}\end{array}}{\delta, \mathrm{ppm}}$} & \multirow{2}{*}{$\begin{array}{c}\begin{array}{c}\text { Block } \\
\text { copolymer }^{\mathrm{d}}\end{array} \\
\delta, \mathrm{ppm}\end{array}$} \\
\hline & & & & \\
\hline a & - & 176.98 & 176.62 & 177.03 \\
\hline $\mathrm{b}$ & 174.74 & - & $175.28,174.77$ & 174.82 \\
\hline c & 79.87 & - & $80.31, \quad 79.92$ & 79.85 \\
\hline d & 78.08 & - & 78.15 & 78.12 \\
\hline $\mathrm{e}$ & - & 40.66 & $40.54, \quad 39.84$ & 40.59 \\
\hline f & - & 34.96 & 34.69 & 34.89 \\
\hline g & 31.17 & - & 31.27 & 31.17 \\
\hline $\mathrm{h}$ & 29.01 & - & $29.45, \quad 29.08$ & 29.04 \\
\hline $\mathrm{i}$ & - & 26.83 & $26.85, \quad 26.56$ & 26.80 \\
\hline $\mathrm{j}$ & 23.57 & - & 23.57 & 23.60 \\
\hline \multicolumn{2}{|c|}{$\begin{array}{c}7-10 \% \\
50 \mathrm{MHz} .\end{array}$} & Trifluo & oethanol & $40^{\circ} \mathrm{C}$ \\
\hline 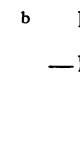 & & $\begin{array}{l}\mathrm{O}_{\mathrm{b}} \\
\mathrm{C} \text { - }\end{array}$ & $\mathrm{H}$ & o \\
\hline
\end{tabular}

c Mole fraction of BOL unit in the copolymer, $m=0.66$. d $m=0.42$. 
crostructures are observed in the latter spectrum as listed in Table IV. Therefore it is reasonable to rule out the possibility of frequent depolymerization of polyBOL from the terminal acyllactam group before the initiation for the polymerization of 2-pyrrolidone. The sequence distribution in the block copolymer is also inferred not to be rearranged after the polymerization. Consequently the AB-type block copolymer composed of polyBOL and nylon 4 was efficiently obtained by the anionic polymerization of 2-pyrrolidone activated with polyBOL having an acyllactam-type terminal group.

Thermal Behavior of the Block Copolymer Composed of PolyBOL and Nylon-4 Segments

While nylon-4 prepared by the anionic polymerization of 2-pyrrolidone using $\mathrm{N}$-acylpyrrolidone as an activator is known to be fused with its simultaneous decomposition, ${ }^{14}$ the block copolymer obtained in the present

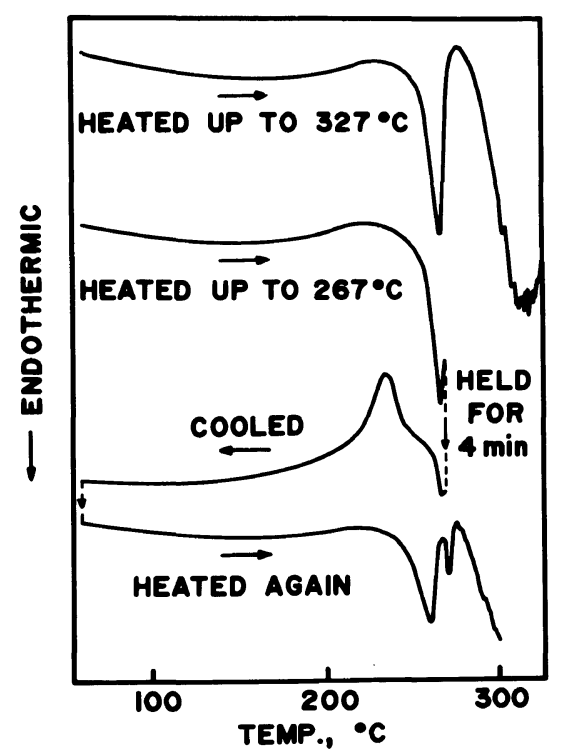

Figure 6. Effect of heat history upon the transition points of AB-type block copolymer composed of polyBOL $\left(M_{n}, 6700\right)$ and nylon-4 segments (weight fraction of $\mathrm{BOL}$ unit, 0.17). Heating or cooling rate, $10^{\circ} \mathrm{C} \mathrm{min}^{-1}$. work has melting and decomposition points at 255-265 and above $285^{\circ} \mathrm{C}$, respectively, as shown in Figure 6. Therefore the copolymer may be applicable to melt spinning.

During the cooling of the copolymer after the fusion at $267^{\circ} \mathrm{C}$, the exothermic peak for recrystallization emerged around $234^{\circ} \mathrm{C}$ (see Figure 6). On rescanning of the sample after the cooling, two transition points were observed at 260 and $269^{\circ} \mathrm{C}$, as shown in Figure 6 , which corresponded to the fusion points of nylon-4 and polyBOL, respectively. The above-described annealing is considered to accelerate the micro-phase separation of the block copolymer having polyBOL and nylon-4 segments.

\section{Crystallization of the Block Copolymer En- hanced by the Water Sorption}

Since polyBOL is more hygroscopic than nylon $-4,{ }^{1}$ the effect of the polyBOL segment upon the water sorption onto the polyBOLnylon-4 block copolymer was also examined as

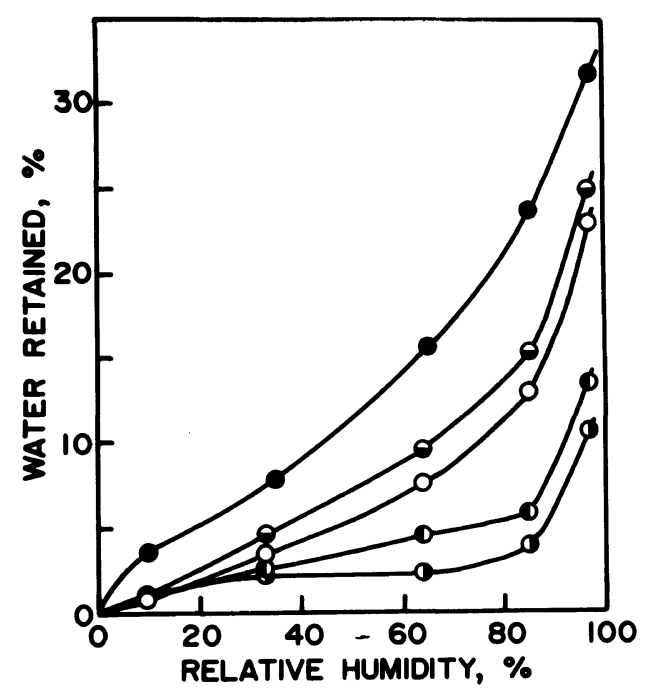

Figure 7. Moisture sorption isotherms of polyBOL, nylon-4, and their AB-type block copolymers at $25^{\circ} \mathrm{C}$ : , PolyBOL; $\bigcirc$, nylon-4; $\ominus$, block copolymer $\left(\bar{M}_{n}\right.$ of polyBOL segment, 4200; weight fraction of BOL unit $(y), 0.35)$; , block copolymer $\left(\bar{M}_{n}\right.$ of polyBOL segment, $8700 ; y=0.30) ; \bigcirc$, block copolymer $\left(\bar{M}_{n}\right.$ of polyBOL segment, 6700; $y=0.17$ ). 


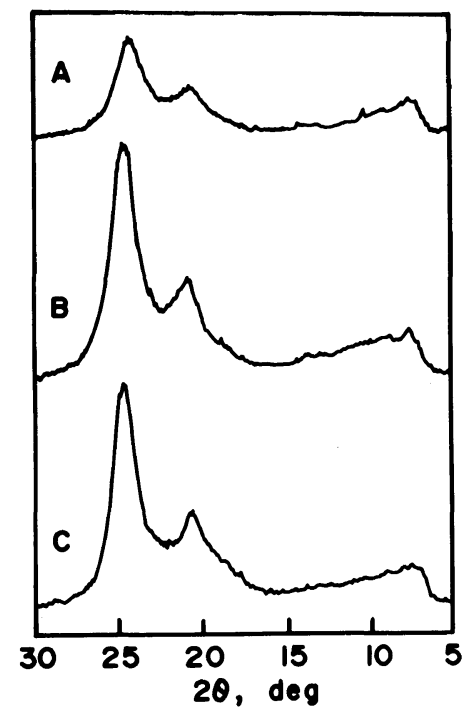

Figure 8. X-Ray diffraction diagrams of AB-type block copolymers composed of polyBOL $\left(\bar{M}_{n}, 6700\right)$ and nylon-4 segments: A, powder stored in a desiccator; B, powder kept for 71 days under the circumstances of room temperature and high lumidity; $\mathrm{C}$, film exposed to the atmosphere at room temperature for 142 days.

shown in Figure 7. The amount of water adsorbed on the copolymer was found to be unexpectedly lower than not only that on polyBOL but also that on nylon- 4 especially at high relative humidity.

Since the crystallinity of $\operatorname{poly}(m$-xylylene adipamide) is known to increase on the adsorption of water, ${ }^{15}$ the X-ray diffraction diagrams of the block copolymers before and after the moisture sorption were taken in Figure 8 (A and B). From their comparison the crystalline peak for the nylon- 4 segment in the copolymer can be regarded to be enhanced while kept in the atmosphere having high relative humidity. In fact, the values of the enthalpy change for fusion of two kinds of the block copolymers in Figure 8 (A and B) were determined by differential scanning calorimetry to be 19.0 and $25.2 \mathrm{cal} \mathrm{g}^{-1}$, respectively.

The crystallinity of the block copolymer film, which was cast from its trifluoroethanol solution at room temperature, also increased during the exposure on the air as shown in Figure $8(\mathrm{C})$ (heat of fusion, $26.6 \mathrm{cal} \mathrm{g}^{-1}$ ). Since the glass transition point of the polyamide is known to drop with the adsorption of water, the high hygroscopicity of the polyBOL domain is speculated to decrease the transition point and increase the movement of the polyBOL segment. The polyBOL domain distributed into the nylon-4 domain may enhance the rearrangement and crystallization of the nylon-4 segment.

Consequently the preparation and isolation of the polyamide having an acyllactam-type terminal group from the bicyclic oxalactam and the chemical modification of the reactive end group were found to be easily controlled. The results should essentially be derived from the living character in the anionic polymerization of the bicyclic oxalactam, which will be published in the near future.

\section{EXPERIMENTAL}

\section{Reagents}

BOL (1) was prepared by the procedure reported earlier ${ }^{1,2}$ and stored over phosphorus pentoxide in vacuo until use. ${ }^{1} \mathrm{H}$ NMR $\left(\mathrm{Me}_{2} \mathrm{SO}-d_{6}\right.$, room temperature) $\delta 8.60(\mathrm{br} \mathrm{s}$, $1 \mathrm{H}$, amide), $5.28\left(\mathrm{~s}, 1 \mathrm{H},{ }^{6} \mathrm{C} \underline{\mathrm{H}}\right), 4.04(\mathrm{~s}, 1 \mathrm{H}$, $\left.{ }^{5} \mathrm{C} \underline{\mathrm{H}}\right), 1.3-2.0 \mathrm{ppm}\left(\mathrm{m}, 6 \mathrm{H}, \mathrm{CH}_{2}\right) ;{ }^{13} \mathrm{C} \mathrm{NMR}$ $\left(\mathrm{Me}_{2} \mathrm{SO}-d_{6}, 39^{\circ} \mathrm{C}\right) \delta 174.65$ (lactamcarbonyl), $84.24\left({ }^{5} \mathrm{C}\right), 73.92\left({ }^{1} \mathrm{C}\right), 27.43\left({ }^{4} \mathrm{C}\right), 23.96\left({ }^{2} \mathrm{C}\right)$, $15.25 \mathrm{ppm}\left({ }^{3} \mathrm{C}\right)$.

Commercially available 2-pyrrolidone was purified through the recrystallization of its monohydrate. ${ }^{16}$ After the pyrolysis of the recrystallized monohydrate, water was removed by the distillation from the mixture and the subsequent azeotropy with xylene. The residual 2-pyrrolidone was first distilled under reduced pressure, and the main fraction was dried over 4A molecular sieves for several days in a high vacuum line twice, followed by redistillation in vacuo.

BzBOL and AcBOL (7) were prepared by the same methods as reported in the previous 
articles. ${ }^{4,5}{ }^{1} \mathrm{H}$ NMR data of BzBOL ( $\mathrm{Me}_{2} \mathrm{SO}-$ $d_{6}$, room temperature) $\delta 7.45-7.7(\mathrm{~m}, 5 \mathrm{H}, \mathrm{Ar})$, $5.98\left(\mathrm{~s}, 1 \mathrm{H},{ }^{5} \mathrm{C} \underline{\mathrm{H}}\right), 4.58\left(\mathrm{br} \mathrm{s}, 1 \mathrm{H},{ }^{1} \mathrm{C} \underline{\mathrm{H}}\right), 1.5-$ $2.1 \mathrm{ppm}\left(\mathrm{m}, 6 \mathrm{H}, \mathrm{CH}_{2}\right) ;{ }^{13} \mathrm{C} \mathrm{NMR}\left(\mathrm{Me}_{2} \mathrm{SO}-d_{6}\right.$, $\left.40^{\circ} \mathrm{C}\right) \quad \delta 171.03 \quad$ (lactam-carbonyl), $\quad 167.00$ (benzoyl-carbonyl), 132.72 (Ar-quarternary), 132.79 (Ar-para), 128.79 and 127.55 (Ar-ortho and meta), 88.52 (lactam- ${ }^{5} \mathrm{C}$ ), 76.59 (lactam$\left.{ }^{1} \mathrm{C}\right), 25.88$ (lactam $\left.-{ }^{4} \mathrm{C}\right), 23.94$ (lactam $-{ }^{2} \mathrm{C}$ ), $15.29 \mathrm{ppm}$ (lactam- ${ }^{3} \mathrm{C}$ ). ${ }^{1} \mathrm{H}$ NMR data of 7 $\left(\mathrm{Me}_{2} \mathrm{SO}-d_{6}\right.$, room temperature) $\delta 5.85(\mathrm{~s}, 1 \mathrm{H}$, $\left.{ }^{5} \mathrm{C} \underline{\mathrm{H}}\right), 4.51$ (br s, $\left.1 \mathrm{H},{ }^{1} \mathrm{C} \underline{\mathrm{H}}\right), 2.44\left(\mathrm{~s}, 3 \mathrm{H}, \mathrm{CH}_{3}\right)$, $1.5-2.0 \mathrm{ppm}\left(\mathrm{m}, 6 \mathrm{H}, \mathrm{C}_{2}\right)$. Potassium pyrrolidonate was obtained as described in the literature. $^{17}$

$N, N^{\prime}$-Terephthaloylbis(8-oxa-6-azabicyclo[3.2.1]octan-7-one) was synthesized by the reaction of $\mathrm{BOL}(5.6 \mathrm{~g})$ with terephthaloyl dichloride $(4.1 \mathrm{~g})$ in the benzene-pyridine mixture $(48 \mathrm{ml} / 4.8 \mathrm{ml})$ at room temperature for $20 \mathrm{~h}$ and recrystallized from THF: yield $2.3 \mathrm{~g}(30 \%)$; mp $213-217^{\circ} \mathrm{C}$. Elemental analysis. Calcd. for $\mathrm{C}_{20} \mathrm{H}_{20} \mathrm{~N}_{2} \mathrm{O}_{6}: \mathrm{C}, 62.48 \%$; $\mathrm{H}, 5.25 \%$; N $7.29 \%$. Found: C, $62.46 \%$; $5.29 \%$; N, $7.21 \% .{ }^{1} \mathrm{H}$ NMR $\left(\mathrm{Me}_{2} \mathrm{SO}-d_{6}\right.$, room temperature) $\delta 7.73(\mathrm{~s}, 4 \mathrm{H}, \mathrm{Ar}), 6.00(\mathrm{br} \mathrm{s}, 2 \mathrm{H}$, lactam- $\left.{ }^{5} \mathrm{C} \underline{\mathrm{H}}\right), 4.56$ (bs, $2 \mathrm{H}$, lactam $\left.-{ }^{1}{ }^{\mathrm{C}} \underline{\mathrm{H}}\right), 1.5-$ $2.1 \mathrm{ppm}\left(\mathrm{m}, 12 \mathrm{H}, \mathrm{CH}_{2}\right) ;{ }^{13} \mathrm{C} \mathrm{NMR}\left(\mathrm{Me}_{2} \mathrm{SO}-d_{6}\right.$, $\left.38^{\circ} \mathrm{C}\right) \delta 171.03 \quad$ (lactam-carbonyl), 166.13 (phthaloyl-carbonyl), $135.83 \quad\left(\mathrm{Ar}-{ }^{1} \mathrm{C},{ }^{4} \mathrm{C}\right)$, 128.04 ( $\left.\mathrm{Ar}-{ }^{2} \mathrm{C},{ }^{3} \mathrm{C},{ }^{5} \mathrm{C},{ }^{6} \mathrm{C}\right), 88.32$ (lactam- $-{ }^{5} \mathrm{C}$ ), 76.50 (lactam- $\left.{ }^{1} \mathrm{C}\right), 25.7 .3$ (lactam- $\left.{ }^{4} \mathrm{C}\right), 23.94$ (lactam- $\left.{ }^{2} \mathrm{C}\right), \quad 15.22 \mathrm{ppm}$ (lactam- $\left.{ }^{3} \mathrm{C}\right) . \quad N, N^{\prime}-$ Terephthaloyl-bis( $\varepsilon$-caprolactam) was prepared by a similar reaction of $\varepsilon$-caprolactam $(5.4 \mathrm{~g})$ with terephthaloyl dichloride $(4.1 \mathrm{~g})$ : yield $5.2 \mathrm{~g}(72 \%) ; \mathrm{mp} 201-202^{\circ} \mathrm{C}$ (lit. ${ }^{18}$ $\left.194.5-195.5^{\circ} \mathrm{C}\right)$.

$N$-Butyl-6-benzoylaminotetrahydropyran-2carboxamide (6) was prepared by reaction of benzamide $(3.6 \mathrm{~g})$ with $\mathrm{N}$-butyl-3,4-dihydo$2 H$-pyran-2-carboxamide $(5.5 \mathrm{~g})$ catalyzed by $p$-toluenesulfonic acid in benzene at $80^{\circ} \mathrm{C}$ for 3h. After the elutional fractionation it was recrystallized from ethyl acetate: ${ }^{19}$ yield, $2.3 \mathrm{~g}$ $(30 \%)$; mp $149-151^{\circ} \mathrm{C}$. Elemental analysis.
Calcd for $\mathrm{C}_{17} \mathrm{H}_{24} \mathrm{~N}_{2} \mathrm{O}_{3}: \mathrm{C}, 67.08 \% ; \mathrm{H}, 7.95 \%$; $9.20 \%$. Found: C, $67.09 \%$;, $7.91 \% ; \mathrm{N}$, $9.35 \% .{ }^{1} \mathrm{H}$ NMR $\left(\mathrm{Me}_{2} \mathrm{SO}-d_{6}\right.$, room temperature) $\delta 9.01(\mathrm{~d}, J(\mathrm{~N} \underline{\mathrm{H}}-\mathrm{C} \underline{\mathrm{H}})=8.5 \mathrm{~Hz}, 1 \mathrm{H}, \mathrm{Ar}-\mathrm{C}$ $(=\mathrm{O})-\mathrm{NH}-), 7.95$ (d, J(ortho-meta) $=7.4 \mathrm{~Hz}$, 2H, Ar-ortho), 7.3-7.8 (m, 4H, Ar-meta, para, and $\left.-\mathrm{C}(=\mathrm{O})-\mathrm{N} \underline{\mathrm{H}}-\mathrm{CH}_{2}-\right), 5.30(\mathrm{~m}, 1 \mathrm{H},-\mathrm{NH}-$ $\mathrm{C} \underline{\mathrm{H}}-\mathrm{O}-), 3.95\left(\mathrm{~b}, J\left(\mathrm{C} \underline{\mathrm{H}}-\mathrm{C}_{2}\right)=10.7 \mathrm{~Hz}, 1 \mathrm{H}\right.$, $-\mathrm{O}-\mathrm{C} \mathrm{H}-\mathrm{C}(=\mathrm{O})-), 3.08\left(\mathrm{~m}, 2 \mathrm{H},-\mathrm{NH}-\mathrm{CH}_{2}-\right)$, $1.05-2.05\left(\mathrm{~m}, 10 \mathrm{H}\right.$, pyran- $\mathrm{CH}_{2}$ and $-\mathrm{NH}-$ $\left.\mathrm{CH}_{2} \mathrm{CH}_{2} \mathrm{CH}_{2} \mathrm{CH}_{3}\right), \quad 0.85 \mathrm{ppm} \quad\left(\mathrm{t}, \quad J\left(\mathrm{C}_{3}-\right.\right.$ $\left.\mathrm{CH}_{2}\right)=6.8 \mathrm{~Hz}, 3 \mathrm{H}, \mathrm{CH}_{3}$ ).

Dimethyl sulfoxide $\left(\mathrm{Me}_{2} \mathrm{SO}\right)$ and tetrahydrofuran (THF) were dried over calcium hydride and sodium metal, respectively, in a high vacuum line and distilled in vacuo. Acetone was distilled after drying over $4 \mathrm{~A}$ molecular sieves. Acetic acid of commercial origin was used as a terminater after the polymerization.

Isolation of the Polyamide Having an Acyllactam-Type Growable End Group (4)

Under dry nitrogen, $6.35 \mathrm{~g}$ of BOL and $0.06 \mathrm{~g}$ of potassium pyrrolidonate were dissolved in $8 \mathrm{~g}$ of $\mathrm{Me}_{2} \mathrm{SO}$ in a flask. Immediately a BzBOL solution $\left(0.23 \mathrm{~g}\right.$ in $12 \mathrm{~g}$ of $\left.\mathrm{Me}_{2} \mathrm{SO}\right)$ was poured into the solution with stirring. After the polymerization at $25^{\circ} \mathrm{C}$ for $30 \mathrm{~min}$, more than $0.15 \mathrm{~g}$ of fresh acetic acid was added into the flask for quenching and the reaction mixture was poured into a large amount of dry acetone. The resulting colorless polymer was collected by centrifugation at room temperature, washed nimbly with dry actone several times, and dried in vacuo: yield $6.0 \mathrm{~g} ; \bar{M}_{n} 6700$.

\section{Chemical Modification of the Acyllactam Group in PolyBOL}

In order to modify the acyllactam group in polyBOL to the carboxyl group, $0.5 \mathrm{ml}$ of water and $39 \mathrm{mg}(0.72 \mathrm{mmol})$ of sodium methoxide were added into the solution of polyBOL having a terminal acyllactam group $\left(\bar{M}_{n}\right.$ $4200,0.52 \mathrm{~g}$ ) in $3 \mathrm{ml}$ of trifluoroethanol and the mixture was kept at room temperature for overnight. After quenching by the addition of 
$0.9 \mathrm{~g}$ of dichloroacetic acid, the solution was condensed by using rotary evaporator under reduced pressure and poured into a large amount of acetone. The precipitated polyamide was recovered by the centrifugation: yield, $0.50 \mathrm{~g} ; \bar{M}_{n} 4300$.

For the conversion of the acyllactam group into the amide group, $31 \mathrm{mg}(0.42 \mathrm{mmol})$ of $n$ butylamine was added into the solution of the polyamide $\left(\bar{M}_{n} 4200,0.50 \mathrm{~g}\right)$ in $2 \mathrm{ml}$ of $\mathrm{Me}_{2} \mathrm{SO}$. After the aminolysis at $25^{\circ} \mathrm{C}$ for $4.5 \mathrm{~h}$, the polyamide was recovered by the same method as described above: yield, $0.41 \mathrm{~g} ; \bar{M}_{n} 3400$.

Anionic Polymerization of 2-Pyrrolidone Activated by the Polyamide Having a Terminal acyllactam Group

All the following polymerization procedures were carried out in a high vacuum line. The polyamide having a terminal acyllactam group (4) was first dried in a $100 \mathrm{ml}$-three necked, round-bottomed flask for several days at room temperature in vacuo. A trace amount of water still adsorbed on the polyamide was distilled out by the repeated azeotropy with THF, in which the polyamide was slightly swollen. After $0.91 \mathrm{~g}$ of the dried polymeric activator was dissolved in $11.6 \mathrm{~g}$ of 2-pyrrolidone, $0.33 \mathrm{~g}$ of potassium perrolidonate was added and kept at $30^{\circ} \mathrm{C}$ for $24 \mathrm{~h}$. The polymerization was terminated by the addition of water. The resulting gross polymer was ground and immersed in water in order to discard the unreacted 2-pyrrolidone, $\mathrm{Me}_{2} \mathrm{SO}$, and the catalyst residue, and dried in vacuo. The unreacted polyBOL was extracted from the gross polymer with choloroform: copolymer yield, $6.42 \mathrm{~g}$; recovered polyBOL, $0.04 \mathrm{~g}$.

\section{Characterization}

Gel permeation chromatogram was measured with a Hitachi Model 634A highperformance liquid-chromatograph apparatus (column, Shodex GPCA $803 \rightarrow 804$ or GPCA $80 \mathrm{M}, 8 \phi \times 1000 \mathrm{~mm}$; solvent, chloroform). ${ }^{1} \mathrm{H}$ and ${ }^{13} \mathrm{C}$ NMR spectra were recorded on a
JEOL JNM-FX-200 and JNM-FX-100 Fourier transform high resolution spectrometer. The DSC thermogram of the polymer was taken with a Perkin-Elmer Model DSC-2 differential scanning calorimeter. The X-ray diffraction data was recorded with a Rigaku Denki No. 2030/P Geigerflex diffractometer using Ni-filtered $\mathrm{Cu}-K$ radiation. Moisture sorption was determined gravimetrically at $25^{\circ} \mathrm{C}$. The relative humidity was adjusted to a constant value by a saturated aqueous solution of appropriate inorganic salts. ${ }^{20,21}$

\section{REFERENCES}

1. H. Sumitomo and K. Hashimoto, Macromolecules, 10, 1327 (1977).

2. K. Hashimoto and H. Sumitomo, Macromolecules, 13, 786 (1980).

3. K. Hashimoro, H. Sumitomo, and H. Yamamori, Polym. J., 19, 249 (1987).

4. K. Hashimoto, H. Sumitomo, and M. Kawasumi, Polym. Bull., 11, 121 (1984).

5. K. Hashimoto, H. Sumitomo, and M. Kawasumi, Polym J., 17, 1045 (1985).

6. J. Sebenda, J. Macromol. Sci.-Chem., 6, 1145 (1972).

7. H. Sekiguchi, "Ring-Opening Polymerization," Vol. 2, K. J. Ivin and T. Saegusa, Eds., Elsevier, London \& New York, 1984, Chapter 12, p 809.

8. H. K. Hall, Jr., J. Am. Chem. Soc., 80, 6412 (1958).

9. H. K. Hall, Jr., J. Am. Chem. Soc., 82, 1209 (1960).

10. I. Luderwald and G. Pernak, J. Anal. and Appl. Pyrol., 5, 133 (1983).

11. K. Hashimoto and H. Sumitomo, J. Polym. Sci., Polym. Chem. Ed., 22, 1733 (1984).

12. K. Hashimoto and H. Sumitomo, Polym. J., 15, 547 (1983).

13. H. Sumitomo, K. Hashimoto, and Y. Betsuda, Koubunshi Ronbunshu, 39, 807 (1982).

14. K. Dachs and E. Schwartz, Angew. Chem. Int. Ed., 1, 430 (1962).

15. K. Inoue and S. Hoshino, Koubunshi Ronbunshu, 36, 141 (1979).

16. M. Taniyama, T. Nagaoka, K. Takada, and K. Sanuyama, Kougyou Kagaku Zasshi, 65, 415 (1965).

17. H. Sekiguchi, Bull. Soc. Chim. Fr., 1827 (1960).

18. J. Stehlicek, J. Labsky, and J. Sebenda, Collect. Czech. Chem. Commun., 32, 545 (1967).

19. K. Hashimoto, H. Sumitomo, and A. Washio, unpublished data.

20. The Society of Polymer Science, Japan, Ed., "Koubunshi to Suibun (Polymer and Water)," Saiwai Shobou, Tokyo 1972, p 167.

21. F. E. M. O'Brien, J. Sci. Inst., 25, 73 (1948). 